\title{
Keynote: Google Maps and Browser Support for Rich Web Applications
}

\author{
Lars Rasmussen \\ Google \\ lars@google.com
}

\section{Brief Bio}

Lars Eilstrup Rasmussen is a member of Google's technical staff and the lead engineer of the team that created Google Maps. He currently works out of Google's Sydney office and is actively working to expand Google's engineering presence in Australia.

Lars holds a Ph.D. in theoretical computer science from the University of California at Berkeley, which nominated his thesis on approximate counting for the ACM Doctoral Dissertation Award.

In early 2003, Lars co-founded with his brother Jens Eilstrup Rasmussen a mapping-related startup, Where 2 Technologies, which was acquired by Google in October of 2004.

\section{Talk Abstract}

Lars designed and built the original prototype of Google Maps, which launched this January as a Google Labs experiment. He will discuss why his team chose a javascript-heavy approach, the challenges of doing so, and how browsers might develop in the future to better support rich web applications such as Google Maps. 